\title{
A TNF receptor loop peptide mimic blocks RANK ligand-induced signaling, bone resorption, and bone loss
}

\author{
Kazuhiro Aoki, ${ }^{1,2}$ Hiroaki Saito, ${ }^{2}$ Cecile Itzstein, ${ }^{1}$ Masaji Ishiguro, ${ }^{3}$ Tatsuya Shibata, ${ }^{4}$ \\ Roland Blanque, ${ }^{5}$ Anower Hussain Mian, ${ }^{2}$ Mariko Takahashi, ${ }^{2}$ Yoshifumi Suzuki, ${ }^{6}$ \\ Masako Yoshimatsu, ${ }^{7}$ Akira Yamaguchi, ${ }^{8}$ Pierre Deprez, ${ }^{5}$ Patrick Mollat, ${ }^{5}$ \\ Ramachandran Murali, ${ }^{9}$ Keiichi Ohya, ${ }^{2}$ William C. Horne, ${ }^{1}$ and Roland Baron ${ }^{1,5}$
}

1Departments of Cell Biology and Orthopaedics, Yale University School of Medicine, New Haven, Connecticut, USA. ${ }^{2}$ Department of Hard Tissue Engineering, Section of Pharmacology, Graduate School, Tokyo Medical and Dental University, Tokyo, Japan. ${ }^{3}$ Suntory Institute for Bioorganic Research, Osaka, Japan. ${ }^{4}$ Department of Pharmacology, Tsurumi University, School of Dental Medicine, Yokohama, Japan. ${ }^{5}$ ProStrakan Pharmaceuticals, Paris, France.

${ }^{6}$ Section of Periodontology, Graduate School, Tokyo Medical and Dental University, Tokyo, Japan. ${ }^{7}$ Department of Developmental and Reconstructive Medicine, Orthodontics, Nagasaki University, Nagasaki, Japan. ${ }^{8}$ Department of Oral Restitution, Section of Oral Pathology, Graduate School,

Tokyo Medical and Dental University, Tokyo, Japan. ${ }^{9}$ Department of Pathology and Laboratory Medicine,

University of Pennsylvania School of Medicine, Philadelphia, Pennsylvania, USA.

\begin{abstract}
Activating receptor activator of NF- $K B$ (RANK) and TNF receptor (TNFR) promote osteoclast differentiation. A critical ligand contact site on the TNFR is partly conserved in RANK. Surface plasmon resonance studies showed that a peptide (WP9QY) that mimics this TNFR contact site and inhibits TNF- $\alpha$-induced activity bound to RANK ligand (RANKL). Changing a single residue predicted to play an important role in the interaction reduced the binding significantly. WP9QY, but not the altered control peptide, inhibited the RANKLinduced activation of RANK-dependent signaling in RAW 264.7 cells but had no effect on M-CSF-induced activation of some of the same signaling events. WP9QY but not the control peptide also prevented RANKLinduced bone resorption and osteoclastogenesis, even when TNFRs were absent or blocked. In vivo, where both RANKL and TNF- $\alpha$ promote osteoclastogenesis, osteoclast activity, and bone loss, WP9QY prevented the increased osteoclastogenesis and bone loss induced in mice by ovariectomy or low dietary calcium, in the latter case in both wild-type and TNFR double-knockout mice. These results suggest that a peptide that mimics a TNFR ligand contact site blocks bone resorption by interfering with recruitment and activation of osteoclasts by both RANKL and TNF.
\end{abstract}

\section{Introduction}

The TNF receptor (TNFR) superfamily member receptor activator of NF-KB (RANK) (1) is expressed on osteoclasts and their precursors, hematopoietic precursors, dendritic cells, and mammary epithelial precursors. RANK ligand (RANKL [ref. 2], also known as OPGL, ODF, and TRANCE [refs. 3-5]) is a TNF-like protein that is expressed by osteoblasts, bone marrow stromal cells, and $\mathrm{T}$ cells. RANKL is synthesized as an integral membrane protein and is active both in its membrane-bound form and when released from its membrane anchor by specific proteases. Both RANK and RANKL are absolutely required for osteoclast differentiation in vitro and in vivo (refs. 4, 5; reviewed in refs. 2, 6, 7). Another TNF family member, TNF- $\alpha$, enhances the osteoclastogenic response to low levels of RANKL (8) and contributes significantly to bone loss

Nonstandard abbreviations used: BMD, bone mineral density; CRD, cysteine-rich domain; NFATc1, nuclear factor of activated T cells c1; OPG, osteoprotegerin; OVX, ovariectomy, ovariectomized; $\mathrm{pQCT}$, peripheral quantitative computed tomography; RANK, receptor activator of NF-אB; RANKL, RANK ligand; sRANKL, soluble RANKL; TNFR, TNF receptor; TNFR(I), p55 type I TNFR; TNFR(II), p75 type II TNFR; TRAP, tartrate-resistant acid phosphatase; $\mathrm{Tyr}^{6}$, tyrosine residue in position 6 .

Conflict of interest: The research reported here was supported in part by ProStrakan Pharmaceuticals (previously ProSkelia Pharmaceuticals). P. Deprez, R. Blanque, P. Mollat, and R. Baron are currently or were previously employed by ProStrakan Pharmaceuticals and, as such, also own stock options in that company. M. Ishiguro received funding from Suntory Institute for Bioorganic Research.

Citation for this article: J. Clin. Invest. 116:1525-1534 (2006). doi:10.1172/JCI22513. induced by ovariectomy (OVX) $(9,10)$ or by inflammation (11-13). RANKL also increases bone resorption by mature osteoclasts (14). The decoy receptor osteoprotegerin (OPG), a soluble homolog of RANK, prevents RANK activation, osteoclastogenesis, and bone resorption by binding to RANKL and preventing the RANKLRANK interaction $(15,16)$. The relative levels of RANKL and OPG largely determine the number of active osteoclasts in bone and consequently, the amount of bone resorption that occurs $(4,15,17)$.

Like other TNF superfamily members $(18,19)$, the active form of RANKL is a homotrimer (20). Conformations of several superfamily members have been determined, in some cases in complexes with their receptors (20-24). The core folding of family members is highly conserved, but the residues on the external faces of the subunits and the conformations of the loops that connect the $\beta$-strands show little conservation between family members $(18,19)$, consistent with the role of these regions in determining binding specificity.

There is also little sequence homology among TNFR superfamily ligand-binding domains other than disulfide-bonded cysteines and a few other residues that are critical for the folding of characteristic repeated cysteine-rich domains (CRDs) (25). Mutagenesis, molecular modeling studies, and crystal structures of p55 type I TNFR/ TNF- $\beta$ [TNFR(I)/TNF- $\beta](22)$ and TRAIL/death receptor $5(23,24)$ complexes indicate that TNFR members have 2 ligand contact surfaces at conserved locations (CRD2 and CRD3 in the TNFR). While the locations and general nature of the 2 contact surfaces are simi- 
A

TNFR(I) 96 CGCRKNQYRHYWSENLFQCFNC---SLC 120

RANK 113 CACTAGYH---WSQDCECCRRN---TEC 134

OPG CECKEGRYL----EIEFCLKH---RSC

CD40 CTCEEGWHCT-----SEACESCVLGRSC

Fas CRCKPNFF--CNS---TVCEHCDPCTGC

DR5 CQCEEGTFREEDSPEM--CRKCR - - TGC
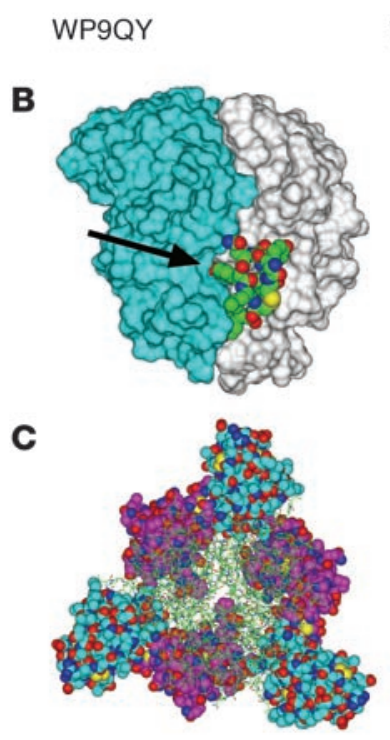

RANKL-RANK
YCWSQYLCY
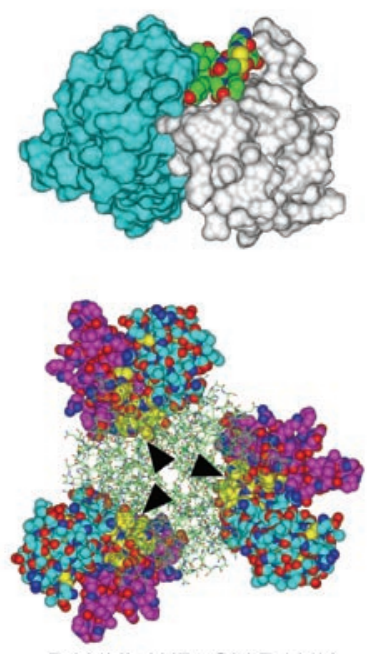

RANKL-WP9QY-RANK

lar among the characterized family members, the specific sequences and conformations of the receptor and ligand loops that mediate the interactions are largely different $(20,23,24)$, accounting for the specificity of the receptor-ligand interactions.

The TNFR(I) CRD3 contact site, which binds to the TNF trimer near its distal end, consists of a few residues within loop 1 of the CRD that bind to a shallow depression at the interface of the 2 TNF subunits (22). Takasaki and colleagues have shown that a small cyclic peptide modeled on this loop, denoted WP9QY, inhibits TNF- $\alpha$-induced cytotoxicity (26). Aligning the TNFR CRD 3 folddetermining residues with homologous sequences of RANK, OPG, and other TNFR family members (Figure 1A) shows that key features of the TNFR(I) contact point, particularly Trp107 and Ser108, are also present in RANK, but not in OPG or the other receptors.

While the specific residues that form the RANK and RANKL contact points have not been determined, the similarity of the RANK and TNFR(I) sequences suggested that the WP9QY peptide mimic of the TNFR(I) loop might bind to RANKL and inhibit the activation of RANK by RANKL. Molecular modeling supported that possibility, and we therefore examined the peptide's effect on RANKL-induced signaling and on osteoclastogenesis and bone resorption both in vitro and in vivo. We found that WP9QY indeed inhibited soluble RANKL-induced (sRANKL-induced) signaling mechanisms as well as sRANKL-induced osteoclastogenesis and bone resorption in vitro. Finally, treatment of mice with the peptide prevented bone loss induced by low dietary calcium, regardless of whether the animals expressed TNFRs, or by OVX. Our results indicate that the ligand contact point function of the CRD3 loop in TNFR and death receptor 5 is conserved in RANK and suggest that interfering with the RANK CRD3 loop interac-

\section{Figure 1}

WP9QY is predicted to bind to RANKL and alter the conformation of the RANKL-RANK complex. (A) Comparison of the sequence of peptide WP9QY with the corresponding sequences of domain 3 of $\operatorname{TNFR}(\mathrm{I})$, RANK, OPG, CD40, Fas, and death receptor 5 (DR5). The residues in the TNFR and RANK that are homologous to the peptide are underlined. OPG, CD40, Fas, and DR5 lack the sequence in loop 1 that is mimicked by WP9QY. (B) Space-filling model of the RANKLWP9QY complex. Two RANKL monomers are shown (blue and white). The WP9QY atoms are colored green (carbon), red (oxygen), blue (nitrogen), and yellow (sulfur). Left: side view, with the complex oriented as if it were bound to RANK on the surface of a cell located below the complex; right: view of the complex rotated $90^{\circ}$ with the bottom of the left image toward the viewer. The arrow indicates the location of $\mathrm{Tyr}^{6}$, which the modeling predicts to play an important role in WP9QYRANKL binding. (C) Modeled complexes of RANK and RANKL extracellular domains with (right) and without (left) WP9QY. RANK and WP9QY are shown as space-filling models; RANKL is shown as a wire model. The complexes are viewed looking toward the RANK-expressing cell. The locations of the WP9QY peptides are indicated (arrowheads). Carbon atoms of RANK's N-terminal and C-terminal domains are colored light blue and magenta, respectively. WP9QY and RANKL carbon atoms are colored yellow and green, respectively.

tion with RANKL in vivo can prevent normal RANKL-induced signaling and modulation of osteoclast differentiation and function. Indeed, interfering with both TNF- and RANKL-induced signaling would provide a potent therapeutic approach to hyperresorptive diseases, including rheumatoid arthritis and periodontal disease.

\section{Results}

Molecular modeling predicts that the WP9QY peptide binds to RANKL and alters the conformation of RANKL-occupied RANK. The folding of members of the TNFR and TNF superfamilies and the locations of the receptor-ligand contact sites are highly conserved (27), with the specificity of the receptor-ligand interactions determined by specific differences in the sequences and conformations of the receptor and ligand loops that mediate the receptor-ligand interactions $(20,23,24)$. The presence in RANK of key features of the TNFR(I) CRD3 contact point, particularly Trp107 and Ser108 (Figure 1A), suggested that the small cyclic WP9QY peptide modeled on the TNFR(I) CRD3 loop, which binds TNF- $\alpha$ and inhibits TNF- $\alpha$-induced cytotoxicity (26), might also bind RANKL and alter RANKL-induced cell responses. The highly conserved folding of members of the TNFR and TNF superfamilies allows the structural modeling of receptor-ligand complexes that have not yet been experimentally characterized $(28,29)$. We therefore used computer modeling to initially examine the possibility that the WP9QY peptide could bind to the RANKL trimer and thereby affect the RANKL-RANK complex. A model of the RANKL-WP9QY complex created by homology modeling from the crystal structure of the TNFR/TNF- $\beta$ complex (Figure 1B) indicated that the peptide would dock snugly into the cleft between RANKL subunits and that tyrosine residues in positions 6 and 9 of the peptide could play important roles in the binding of the peptide to RANKL.

The model of the RANKL-RANK complex in the absence of the peptide showed RANK binding along the entire length of the lateral face of the RANKL trimer, with the C-terminal (membraneproximal) portions of the 3 RANK molecules converging below the more narrow end of the RANKL trimer (Figure 1C, left), consistent with the known RANKL-induced clustering of the RANK 

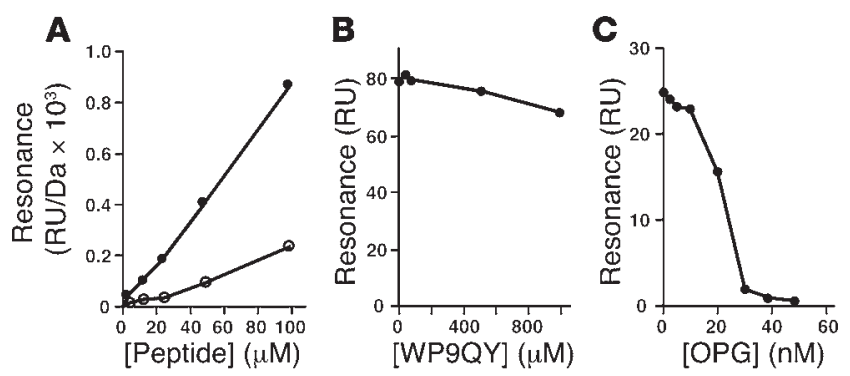

cytoplasmic domains. Superimposing the RANKL moieties of the RANKL-WP9QY peptide complex and the RANKL-RANK complex (Figure 1C, right) suggested that the presence of the peptide in the cleft between the RANKL monomers would interfere with the binding of the C-terminal portion of the RANK extracellular domain involving the CRD3 loop region, but not with the second receptor-ligand contact site at the more distal point of the RANK extracellular domain. In the model, the presence of the peptide displaced the C-terminal portion of the extracellular domain, increasing the distance between the $\mathrm{C}$ termini of the ligandbound RANK extracellular domains. (Compare the left and right images in Figure 1C.)

WP9QY binds to sRANKL but does not inbibit RANKL-RANK binding. We measured the binding of WP9QY to RANKL and its effect on the RANKL-RANK interaction using surface plasmon resonance. sRANKL bound to WP9QY immobilized on the biosensor surface $\left(K_{d}=0.437 \pm 0.013 \mu \mathrm{M}\right)$. Changing the tyrosine residue in position $6\left(\mathrm{Tyr}^{6}\right)$ to asparagine (Y6N) reduced the binding to RANKL by more than $70 \%$ at concentrations up to $50 \mu \mathrm{M}$ (Figure $2 \mathrm{~A}$ ), consistent with the model's prediction that this tyrosine is important for the binding. However, despite its ability to bind to RANKL, WP9QY failed to displace RANK from RANKL (Figure 2B), consistent with the model's indication that the peptide would block

\section{Figure 3}

WP9QY blocks RANKL-induced signaling. (A) RAW 264.7 cells treated with SRANKL with or without WP9QY were stained with anti-p65 antibody (green) and nuclear stain (blue). WP9QY prevented RANKLinduced nuclear accumulation of p65. (B) RAW 264.7 cells were treated with sRANKL with or without WP9QY $(10 \mu \mathrm{M}$ or $25 \mu \mathrm{M})$ or OPG. EMSA was performed using a consensus NF-KB oligonucleotide probe. WP9QY prevented the RANKL-induced activation of NF-KB. (C) Nonadherent bone marrow cells differentiated with M-CSF were treated for 48 hours with $100 \mathrm{ng} / \mathrm{ml}$ RANKL alone or with WP9QY (10 $\mu \mathrm{M}$ or $25 \mu \mathrm{M})$ or OPG. NFATc1 and c-Fos were detected by Western blotting. WP9QY inhibited RANKL-induced NFATc1 and c-Fos expression, albeit less effectively than OPG. (D) RAW 264.7 cells were treated with M-CSF ( $20 \mathrm{ng} / \mathrm{ml}$ for 5 minutes) or sRANKL, with or without $50 \mu \mathrm{M}$ WP9QY as indicated. Phosphorylated and total Erk1/2 (upper panels) or phosphorylated and total glycogen synthase kinase $3 \alpha / \beta$ (GSK3 $\alpha / \beta$; lower panels) were assayed. WP9QY did not affect M-CSF-induced activation of Erk or Akt. (E) RAW 264.7 cells were treated with sRANKL with or without WP9QY $(5-50 \mu \mathrm{M})$, the control Y6N peptide, or OPG as indicated. Erk, JNK, and Akt activation were monitored as described in Methods. Upper panels: phosphorylated and total Erk and phosphorylated and total c-Jun. The control peptide inhibited RANKL-induced activation of Erk1/2 and JNK significantly less than WP9QY. Lower panels: phosphorylated GSK3 $\alpha / \beta$. Protein loading was monitored by Ponceau $S$ staining before blocking the membrane. WP9QY inhibited the RANKL-induced activation of Akt.

\section{Figure 2}

WP9QY binds to RANKL but cannot prevent the interaction between RANKL and RANK. (A) The direct binding of sRANKL to the WP9QY peptide (filled circles) and to the $\mathrm{Y} 6 \mathrm{~N}$ control peptide (open circles) was examined by surface plasmon resonance, as described in Methods. Changing the Tyr residue to Asn reduced the binding by more than $70 \%$. (B) The binding of RANKL (600 ng/ml) to the sRANK-coated surface was measured in the presence of increasing concentrations of WP9QY. Concentrations of WP9QY as high as $1 \mathrm{mM}$ failed to significantly reduce the binding of sRANKL to RANK. (C) OPG effectively blocked the binding of sRANKL to RANK in a dose-dependent manner.

the CRD3 contact site but have no effect on the CRD2 contact site. In contrast to the insensitivity of RANKL-RANK binding to WP9QY, the RANKL-RANK complex was completely disrupted by the decoy receptor OPG (Figure $2 \mathrm{C}$ ).

WP9QY blocks RANKL-induced signaling. Since WP9QY bound to RANKL, we asked whether the peptide affects RANKL-induced signaling, notwithstanding the fact that it failed to displace RANK from RANKL. In the osteoclast precursor RAW 264.7 cell line, WP9QY acted in a dose-dependent manner to inhibit the sRANKL-

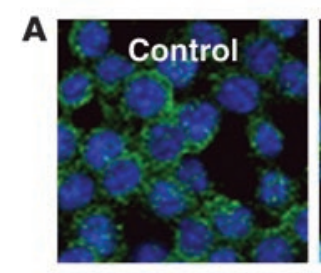

B

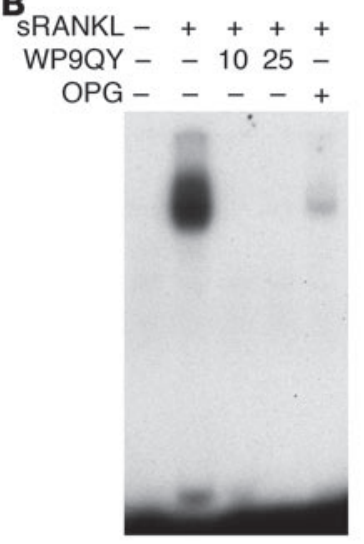

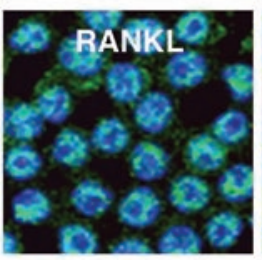

C WP9QY - -1025 $\mathrm{OPG}-\ldots+$ NFATC1$\begin{array}{ll}\text { c-Fos }- & =-= \\ \text { Actin } & =-\infty\end{array}$

D

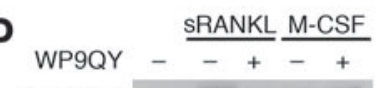
P-Erk1/2 $=-$ Erk2 - P-GSK3 $\alpha / \beta \quad-\infty$ GSK3 $\alpha / \beta=20$
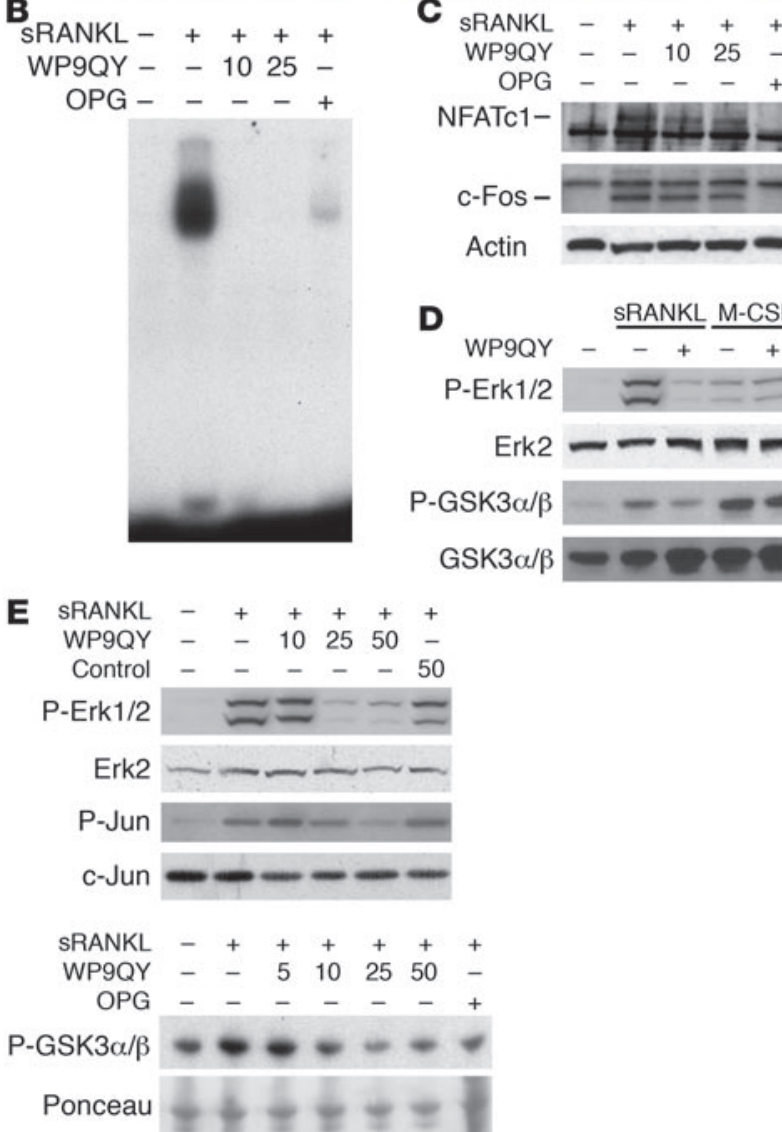


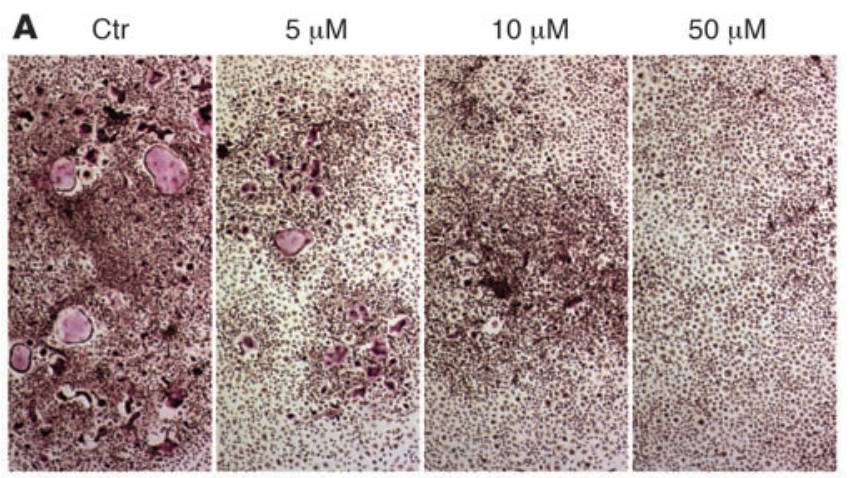

B

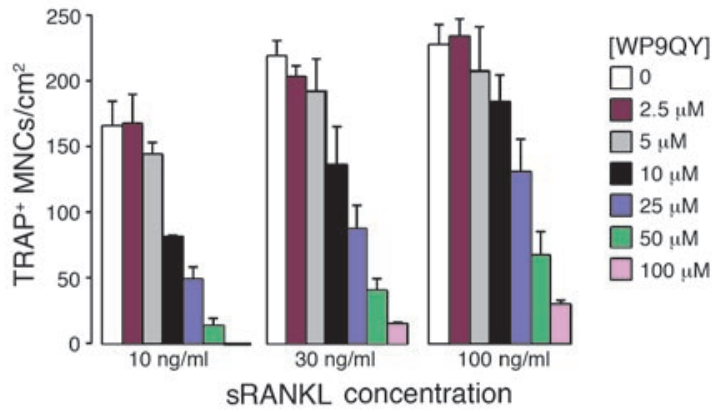

C

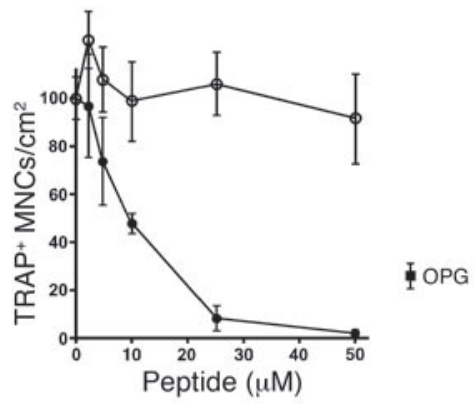

induced translocation of $\mathrm{p} 65$, a major component of NF- $\mathrm{kB}$, to the nucleus (Figure $3 \mathrm{~A}$ ); the sRANKL-induced activation of NF- $\mathrm{KB}$ (Figure 3B); and the sRANKL-induced increases in nuclear factor of activated T cells c1 (NFATc1) expression (Figure 3C), Erk phosphorylation, and JNK and Akt kinase activities (Figure 3, D and E). The effect of WP9QY was not due to a general reduction of cell signaling potency, since it had no effect on M-CSF-induced Erk or Akt activation (Figure 3D). Furthermore, the $\mathrm{Y} 6 \mathrm{~N}$ control peptide had little or no inhibitory effect (Figure 3E). Thus, despite its failure to prevent RANKL-RANK binding, the WP9QY peptide effectively and specifically inhibited RANKL-induced signaling.

WP9QY inbibits soluble RANKL-induced osteoclastogenesis and bone resorption in vitro. We next examined the effect of the peptide on RANKL-induced osteoclastogenesis in vitro. Murine bone marrow cells were cultured for 5 days with $25 \mathrm{ng} / \mathrm{ml} \mathrm{M}$-CSF and 10, 30 , or $100 \mathrm{ng} / \mathrm{ml}$ sRANKL alone or with increasing concentrations of the peptide, and tartrate-resistant acid phosphatase-positive (TRAP-positive) multinucleated cells were counted (Figure 4, $A$ and B). WP9QY inhibited osteoclastogenesis with a clear dose response at each sRANKL concentration tested. The concentration of WP9QY needed to achieve 50\% inhibition increased from $10 \mu \mathrm{M}$ in the presence of $10 \mathrm{ng} / \mathrm{ml}$ sRANKL to more than $25 \mu \mathrm{M}$ in the presence of $100 \mathrm{ng} / \mathrm{ml}$ sRANKL, strongly suggesting that WP9QY inhibited osteoclastogenesis by interfering with RANKL-induced

\section{Figure 4}

WP9QY inhibits SRANKL-induced osteoclastogenesis and bone resorption in vitro. (A) Murine bone marrow cells from CD-1 mice were cultured in the presence of M-CSF $(25 \mathrm{ng} / \mathrm{ml})$ and sRANKL $(10 \mathrm{ng} / \mathrm{ml})$. Increasing amounts of WP9QY were included as indicated. After 4 days, the cells were fixed and stained for TRAP. Ctr, control. (B) Murine bone marrow cells from CD-1 mice were cultured in the presence of M-CSF $(25 \mathrm{ng} / \mathrm{ml})$ and increasing concentrations of $\operatorname{sRANKL}(10,30$, or 100 $\mathrm{ng} / \mathrm{ml}$, as indicated). Increasing amounts of WP9QY were included as indicated. After 4 days, the cells were fixed and stained for TRAP, and the TRAP+ cells were counted. Increasing concentrations of WP9QY progressively inhibited the SRANKL-induced osteoclast formation at all concentrations of SRANKL. Progressively more WP9QY was required to achieve the same degree of inhibition as the concentration of SRANKL increased. The values are the mean \pm SD of triplicate determinations and are representative of 3 independent experiments. (C) Murine bone marrow cells from CD-1 mice were cultured for 4 days in the presence of M-CSF $(25 \mathrm{ng} / \mathrm{ml})$ and sRANKL $(10 \mathrm{ng} / \mathrm{ml})$ with increasing amounts of WP9QY (filled circles) or the control Y6N peptide (open circles) or 30 $\mathrm{ng} / \mathrm{ml}$ OPG. The cells were fixed and stained for TRAP and the TRAP+ multinucleated cells counted.

signaling. In contrast to the effect of WP9QY, which reduced the number of TRAP-positive multinucleated cells by more than $90 \%$ at concentrations equal to or greater than $25 \mu \mathrm{M}$, the $\mathrm{Y} 6 \mathrm{~N}$ control peptide had little effect at concentrations as high as $50 \mu \mathrm{M}$ (Figure $4 \mathrm{C})$. As a positive control, $30 \mathrm{ng} / \mathrm{ml} \mathrm{OPG}$ reduced the number of TRAP-positive multinucleated cells to about $25 \%$ of the numbers in untreated cultures.

sRANKL also stimulates bone resorption by mature osteoclasts (14). We therefore examined the effect of WP9QY and the control peptide on sRANKL-induced bone resorption in vitro (Figure 5). Mature osteoclasts from 3-day-old CD-1 mice were plated on dentin slices and cultured for 24 hours with no addition, with sRANKL (30 $\mathrm{ng} / \mathrm{ml})$ alone, or with sRANKL and WP9QY (50 $\mu \mathrm{M})$, the control peptide $(50 \mu \mathrm{M})$, or OPG $(30 \mathrm{ng} / \mathrm{ml})$. Consistent with previous reports, sRANKL potently stimulated bone resorption; the resorbed area (Figure 5B), resorbed volume (data not shown), and average depth (Figure 5C) of pits were increased by 24-fold, 50-fold, and 2.4-fold, respectively. WP9QY inhibited the increased bone resorption by more than $90 \%$, while the control peptide inhibited the RANKL-induced increase in bone resorption by only $20-30 \%$. In this assay, mature osteoclasts were plated, and the number of osteoclasts was not altered by RANKL alone or in combination any other agent (data not shown).

WP9QY inbibits sRANKL-induced in vitro osteoclastogenesis in the absence of TNFRs. TNF synergizes with low levels of RANKL to induce osteoclast differentiation (8) and can itself induce low levels of osteoclastogenesis in M-CSF-treated bone marrow cultures (30-32). Thus, WP9QY, which inhibits TNFR(I) signaling (26), might affect osteoclastogenesis by inhibiting the effect of endogenous TNF rather than by preventing RANKL-induced RANK signaling. We therefore examined the effect of WP9QY on RANKL-induced osteoclastogenesis from precursors that lacked either the TNFR(I) or the p75 type II TNFR [TNFR(II)]. In the absence of WP9QY, RANKL-induced osteoclastogenesis was reduced by more than half when the osteoclast precursors lacked p55 but not when they lacked p75 (Figure 6A), suggesting that endogenous TNF enhances RANKL-induced osteoclastogenesis in the bone marrow culture system used here. Notwithstanding the reduced osteoclastogenesis seen in the $\mathrm{p} 55^{-/-}$cultures, WP9QY 
A
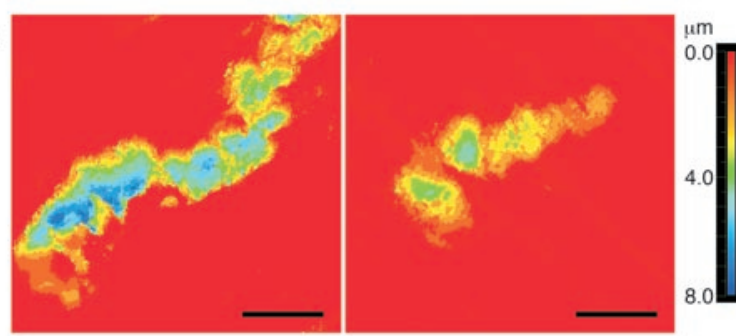

B

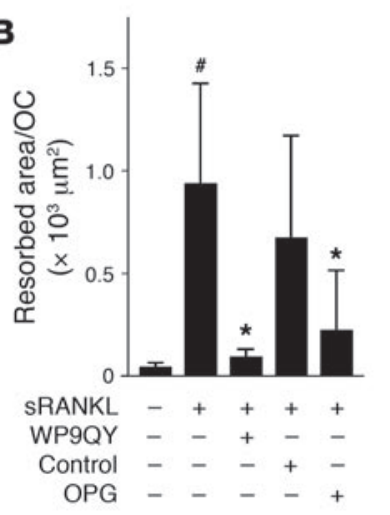

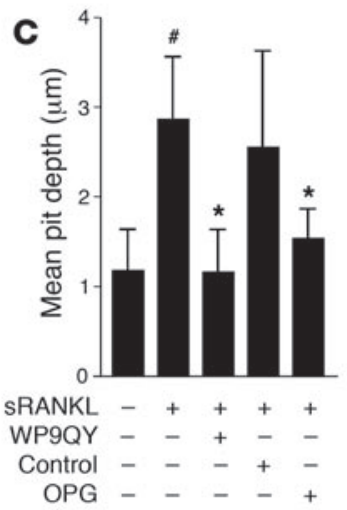

$(5 \mu \mathrm{M})$ inhibited more than $80 \%$ of the sRANKL-induced formation of $\mathrm{TRAP}^{+}$cells in both the $\mathrm{p} 55^{-/}$and $\mathrm{p} 75^{-/}$cultures (Figure $6 \mathrm{~A})$, even when antibodies that blocked $\mathrm{p} 75$ activation were present

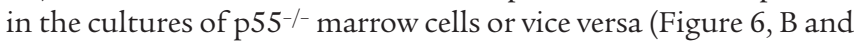
C). Thus, WP9QY inhibited sRANKL-induced osteoclastogenesis even under the conditions where signaling by endogenous TNF is prevented, providing further evidence that the peptide inhibits osteoclastogenesis by blocking RANKL-induced RANK activation, in addition to its known effects on TNF-induced activity.

WP9QY prevents bone loss in vivo, even in the absence of TNF receptors. Given WP9QY's ability to inhibit RANKL-induced osteoclast dif-

\section{Figure 5}

WP9QY inhibits bone resorption by mature osteoclasts in vitro. Authentic osteoclasts were isolated from the long bones of 3-day-old CD-1 mice, plated on dentin slices, and cultured for 48 hours in the presence of the indicated combinations of sRANKL $(30 \mathrm{ng} / \mathrm{ml})$, WP9QY $(50 \mu \mathrm{M})$, control peptide $(50 \mu \mathrm{M})$, and OPG $(30 \mathrm{ng} / \mathrm{ml})$. (A) Typical image of pits formed in the absence (left panel) and presence (right panel) of WP9QY. The resorbed area (B) and resorbed volume (data not shown) were determined, normalized to the number of osteoclasts (OCs) on the dentin slices, and used to calculate the mean pit depth (C). WP9QY blocked the sRANKL-induced increase in bone resorption, while the control peptide did not. The values are the mean \pm SD of 6 dentin slices and are representative of 2 independent experiments. ${ }^{\#} P<0.001$ versus untreated; ${ }^{*} P<0.001$ versus sRANKL alone.

ferentiation and bone resorption in vitro, as well as its previously reported ability to interfere with TNF-induced responses, we asked whether the peptide might prevent bone loss in vivo, examining WP9QY's effect on OVX-induced bone loss, which requires both RANKL- and TNF-induced signaling $(9,15)$, and on bone loss caused by low dietary calcium, which may be less dependent on TNF. Histomorphometry and peripheral quantitative computed tomography (pQCT) analysis demonstrated that the low-calcium diet induced a rapid increase in bone resorption as a consequence of increased osteoclast numbers and activity in mice in a manner similar to what had been previously shown in rats (33) (data not shown). WP9QY had no effect on the body weight or the uterine weight in the OVX mice (data not shown). Treatment with WP9QY completely prevented the bone loss induced by either ovariectomy (Figure 7, A and B, and Table 1) or low dietary calcium (Figure 7, C and D, and Table 2). In both models, WP9QY blocked the experimentally induced increase in deoxypyridinoline cross-links, a marker of bone resorption (data not shown). WP9QY inhibited the decrease in the cancellous bone volume and the increases in bone resorption parameters such as osteoclast surface and osteo-
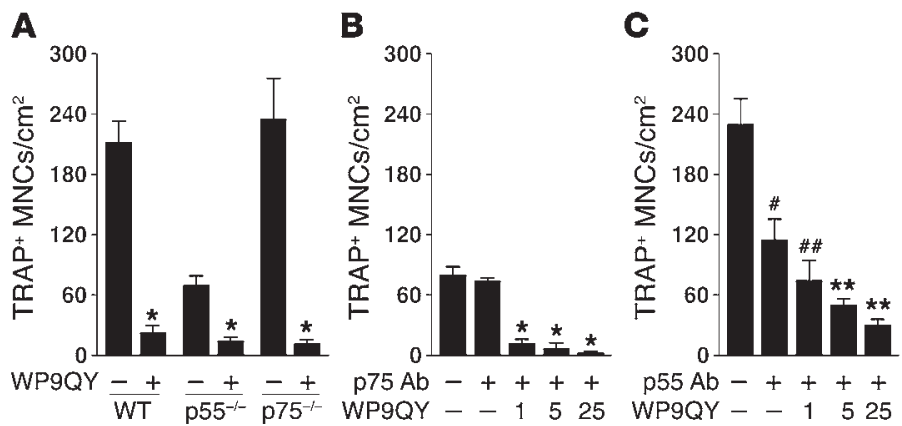

\section{Figure 6}

WP9QY inhibits osteoclastogenesis in bone marrow cultures when TNFRs are missing or blocked. (A) Bone marrow cells from mice that lacked

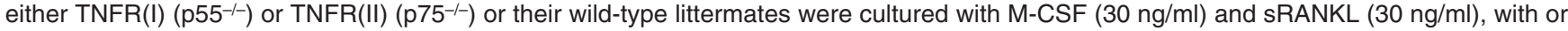
without WP9QY $(5 \mu \mathrm{M})$. In all cases, WP9QY reduced the number of TRAP+ multinucleated cells (MNCs) by more than $80 \%\left({ }^{*} P<0.001\right.$ relative to matched untreated culture). The results are representative of 2 independent experiments. (B) Bone marrow cells from mice that lacked p55 were cultured with an antibody that blocked p75 and increasing concentrations of WP9QY $(\mu \mathrm{M})$ as indicated. The antibody had little additional effect on the number of TRAP+ MNCs produced. All concentrations of WP9QY efficiently inhibited the sRANKL-induced osteoclastogenesis $\left({ }^{\star} P<0.001\right.$ relative to culture with anti-p75 antibody). The results are representative of 2 independent experiments. (C) Bone marrow cells from mice that lacked p75 were cultured with an antibody that blocked p55 and increasing concentrations of WP9QY as indicated. In contrast to the lack of effect of anti-p75 in the p55-/- marrow cultures, anti-p55 significantly reduced the TRAP+ MNC formation from p75 ${ }^{-1-}$ bone marrow cells. WP9QY further inhibited TRAP+ MNC formation in a dose-dependent manner ( $P<0.001$ relative to the cultures in the absence of anti-p55; ${ }^{\# \# P} P<0.02$ relative to culture in the presence of anti-p55; ${ }^{\star \star} P<0.001$ relative to culture in the presence of anti-p55). The results are representative of 2 independent experiments. 
A

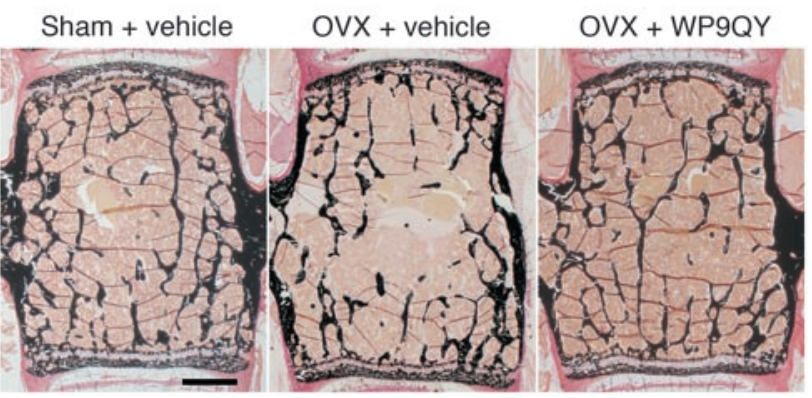

B
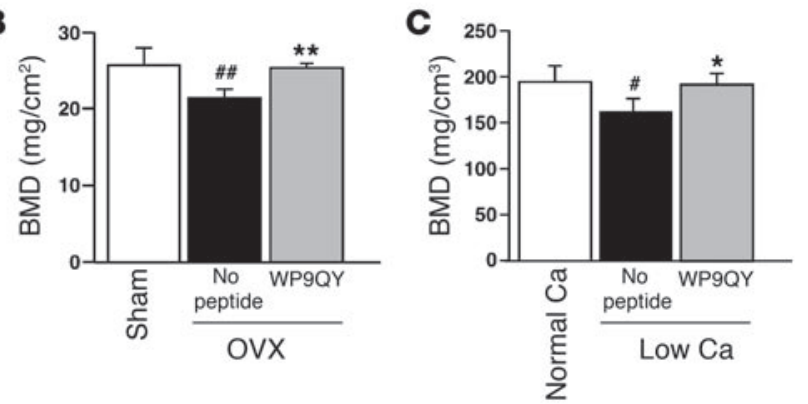

D

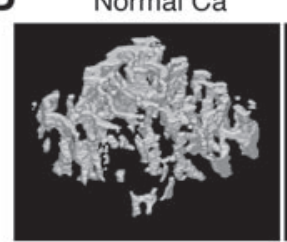

Low $\mathrm{Ca}$ - no peptide Low Ca + WP9QY
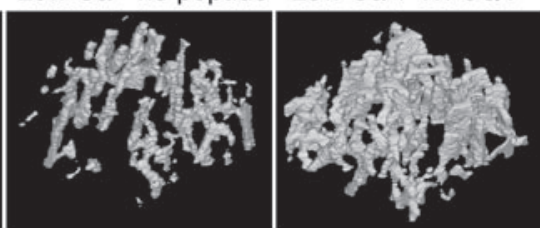

clast number induced by ovariectomy and by the low-calcium diet (Tables 1 and 2, respectively). The effect of the treatment with the peptide was dose dependent, although not all the differences reached statistical significance in the OVX mice that were treated with the lower amount of peptide (data not shown). Thus, WP9QY can inhibit the osteoclastogenesis and bone resorption induced in vivo by either estrogen deficiency or low dietary calcium.

To rule out the possibility that the inhibitory effect of WP9QY on in vivo bone loss was entirely due to inhibition of TNF-induced signaling, we repeated the low-calcium diet experiment in mice that lacked both TNFR(I) and TNFR(II) (Figure 8). The diet-induced bone loss was somewhat less in the mice that lacked both TNFRs than in the genetically matched wild-type animals, consistent with a TNF-dependent component of the response to low calcium. Notwithstanding this difference, WP9QY prevented the diet-induced bone loss as effectively in the mice that lacked both TNFRs as it did in the wild-type mice, while the control peptide had little effect in either set of mice. The bone-sparing effect of WP9QY in the absence of both TNFRs provides additional evidence that the peptide protects mice against bone loss in vivo, at least in part, by inhibiting a TNF-independent mechanism, most likely RANKLinduced osteoclastogenesis and bone resorption.

\section{Discussion}

The absolute requirement for RANKL-induced RANK signaling in osteoclastogenesis is well established and based on a variety of in vitro and in vivo studies, including the deletion of the genes for RANK $(34,35)$ and RANKL $(17)$ and the overexpression of sRANKL-binding proteins $(15,36)$ in transgenic mice. Consis-

\section{Figure 7}

WP9QY inhibits the increased osteoclastogenesis and bone loss induced by ovariectomy or low dietary calcium. The effect of WP9QY on in vivo bone density was determined in ovariectomized mice (A and $\mathbf{B}$ ) or mice fed a low-calcium diet (C and $\mathbf{D})$. Mice were treated with WP9QY $(2.1 \mathrm{mg} / \mathrm{kg} / \mathrm{d}$ continuous infusion for ovariectomized mice; $9 \mathrm{mg} / \mathrm{kg}$ by injection every 3 hours for the low-dietary-calcium mice) or vehicle. (A) Vertebrae from sham-operated mice or ovariectomized mice treated with WP9QY or vehicle were stained for mineralized bone by the von Kossa method with the van Giesson modification. WP9QY $(2.1 \mathrm{mg} / \mathrm{kg} / \mathrm{d})$ significantly inhibited the OVX-induced decrease of cancellous bone. (B and $\mathbf{C}$ ) BMD of the proximal tibiae from ovariectomized mice (B) and from mice maintained on the lowcalcium diet (C) was measured by dual energy X-ray absorptiometry (DEXA) and $\mathrm{pQCT}$, respectively. WP9QY inhibited the decrease in BMD induced by both ovariectomy and by low-calcium diet $(n=5$; ${ }^{\# \#} P<0.01$ versus vehicle-treated sham group; ${ }^{\star \star} P<0.01$ versus vehicle-treated OVX group; $\#<0.05$ versus normal-calcium group; ${ }^{\star} P<0.01$ versus untreated low-calcium group). (D) The 3-dimensional structure of the trabecular bone was examined by micro-computed tomography $(\mu \mathrm{CT})$, as described in Methods. The amount of trabecular bone in the animals maintained on the low-calcium diet without treatment was markedly less that the amount of trabecular bone in animals maintained on the normal-calcium diet. Treatment with WP9QY $(9 \mathrm{mg} / \mathrm{kg})$ prevented the loss of trabecular bone. tent with the key role of RANKL-RANK-dependent signaling in inducing osteoclast formation and promoting osteoclast boneresorbing activity, antagonizing RANKL-induced stimulation of RANK is a potent therapeutic approach to treating conditions that are characterized by excessive bone resorption, such as osteoporosis (37). We report here that a cyclic peptide designed to mimic the CRD3 ligand contact surface of the TNFR that binds to TNF (26) also binds to RANKL and that it inhibits RANKLinduced signaling, RANKL-induced in vitro osteoclastogenesis, and RANKL-stimulated bone resorption by isolated osteoclasts in vitro. The ability to inhibit RANKL-induced cellular responses is relatively specific. The WP9QY peptide does not generally weaken the responsiveness of the cells, since it did not affect signaling induced by M-CSF. In addition, the inhibitory potency of the peptide was markedly reduced by changing a single tyrosine residue, predicted by molecular modeling to be important for binding, to asparagine. Most importantly, WP9QY is fully protective in 3 different strains of mice (CD-1, C57BL/6J, and 129/C57BL/6J) against bone loss induced using 2 different experimental protocols (low dietary calcium and ovariectomy).

Since TNF is known to enhance the response of osteoclast precursors to low concentrations of RANKL (8) and is involved in the bone loss induced by ovariectomy (9), this efficiency is probably linked to its ability to inhibit both RANKL- and TNF-induced responses. Although the ability of WP9QY to inhibit TNF-induced responses (26) complicates the demonstration that WP9QY directly antagonizes RANKL-induced osteoclastogenesis and bone resorption, our results demonstrate that the inhibitory effect of the peptide is at least in part a consequence of the peptide's direct inhibition 


\section{Table 1}

Histomorphometric analysis of the protective effect of WP9QY on bone loss induced by ovariectomy (lumbar vertebra)

\begin{tabular}{|c|c|c|c|}
\hline Parameter & Sham/vehicle & OVX/vehicle & $\begin{array}{l}\text { OVX/WP9QY } \\
(2.1 \mathrm{mg} / \mathrm{kg})\end{array}$ \\
\hline BV/TV (\%) & $16.90 \pm 3.65$ & $9.10 \pm 0.99^{A}$ & $14.79 \pm 5.12^{\mathrm{B}}$ \\
\hline TbTh $(\mu \mathrm{m})$ & $20.3 \pm 1.75$ & $15.07 \pm 2.42^{C}$ & $18.14 \pm 3.82$ \\
\hline TbN (no./mm) & $8.26 \pm 1.24$ & $6.10 \pm 0.60^{A}$ & $8.01 \pm 1.37^{B}$ \\
\hline $\operatorname{TbSp}(\mu \mathrm{m})$ & $103.5 \pm 23.76$ & $150.12 \pm 14.64^{A}$ & $109.998 \pm 25.99 B$ \\
\hline NOc/BS (no./mm) & $2.53 \pm 0.90$ & $7.62 \pm 1.99$ & $3.65 \pm 1.88^{D}$ \\
\hline OcS/BS $(\%)$ & $4.27 \pm 1.71$ & $11.58 \pm 2.99^{A}$ & $5.96 \pm 3.39 \mathrm{~B}$ \\
\hline ObS/BS (\%) & $7.42 \pm 3.02$ & $10.37 \pm 1.55^{C}$ & $9.54 \pm 0.78$ \\
\hline
\end{tabular}

${ }^{A} P<0.005$ versus sham group. ${ }^{B} P<0.05$ versus $O V X$ group. ${ }^{C} P<0.05$ versus sham group. $D P<0.005$ versus $O V X$ group. $B S$, bone surface; $\mathrm{BV}$, bone volume; NOc, osteoclast number; ObS, osteoblast surface; OcS, osteoclast surface; TbTh, trabecular thickness; TbN, trabecular number; TbS, trabecular spacing; TV, tissue volume.

of RANKL-induced responses, since WP9QY was also effective in $\mathrm{TNFR}^{-/}$cells and mice (Figures 6 and 8). In addition, the peptide inhibited RANKL-induced signaling in RAW 264.7 cell cultures (Figure 3). The peptide also inhibited osteoclastogenesis induced by higher concentrations of sRANKL (Figure 4B) that are insensitive to the presence of TNF (8). The reduced osteoclastogenesis in untreated cultures of marrow cells from $\mathrm{p} 55^{-/-}$animals (Figure 6, A and $\mathrm{B}$ ) is consistent with a TNF-dependent component in the osteoclastogenesis in these cultures and suggests that inhibition of both RANKL- and TNF-induced responses contributes to the peptide's ability to inhibit osteoclastogenesis in cultures of wild-type cells.

Demonstrating that WP9QY inhibits RANKL-induced osteoclastogenesis and bone resorption in vivo is similarly difficult. Ovariectomy-induced bone loss is largely or completely dependent on both RANKL (15) and TNF (9), and it is therefore not possible to ascribe the bone-sparing effect of WP9QY in the ovariectomized mice solely to the inhibition of RANKL-induced signaling or of TNF-induced signaling, although the possibility remains that the prevention of ovariectomy-induced bone loss by WP9QY involves the inhibition of both RANKL- and TNF-induced responses. In contrast to ovariectomy-induced bone resorption, however, the bone loss induced by low dietary calcium is not completely dependent on TNF, since low dietary calcium induced a loss of bone in mice that lacked both TNFR(I) and TNFR(II) to a bone mineral density (BMD) similar to that seen in wild-type mice (Figure 8). WP9QY completely blocked the bone loss in the TNFR(I)-/TNFR(II) $)^{-/-}$mice, just as it did in the wild-type mice, demonstrating that the peptide does act independently of TNF-TNFR in vivo, as it does in vitro. The fact that the peptide is able to inhibit both TNF- and RANKL-induced signaling may increase its efficacy relative to agents that inhibit only one or the other mechanism.

Our binding studies indicate that WP9QY inhibits RANKLinduced signaling but not the binding of RANKL to RANK, in contrast to the ability of a peptide modeled on an OPG contact site for RANK to inhibit RANKL-RANK binding (38). The failure of WP9QY to displace RANK from RANKL raises the question of how the peptide affects the interaction of RANKL and RANK at the molecular level and the RANKL-induced activation of RANK.

As noted above, members of the TNFR superfamily bind to their ligands via 2 distinct contact surfaces that are conserved in terms of the relative locations on the proteins but are highly specific in terms of sequence and conformation $(20,22-24,39)$. By analogy with TNF- $\alpha$ and TNF- $\beta(22,40-42)$, the contact between the ligand surface and the receptor CRD2 appears to be the more important for binding and might be sufficient by itself to mediate the binding of the 2 proteins. Consistent with this possibility, mutations in the predicted CRD2-binding surface of RANKL markedly reduce or abolish RANKL's osteoclastogenic activity (20). WP9QY's failure to displace RANK from RANKL was consistent with our molecular modeling, which predicted that the binding of WP9QY to RANKL would have little or no effect on the overall RANK CRD2 interaction with RANKL. However, although by no means conclusive, the modeling predicted that the presence of the peptide in the binding site for CRD3 would displace the membrane-proximal portion of the RANK extracellular domain outward from the central axis of the RANKL trimer, possibly affecting the receptor's signaling activity by interfering with the proposed ligand-induced clustering of the receptor cytoplasmic domains $(27,43,44)$. However, this possibility remains hypothetical until it can be experimentally confirmed.

In conclusion, we have found that a cyclic peptide with sequence homology to a predicted ligand contact surface on RANK inhibits RANKL-induced signaling, osteoclastogenesis, and bone resorption in vitro, suggesting that the first loop of RANK's third CRD is a critical ligand contact point, like the homologous loop in the TNFR. Furthermore, and notwithstanding the poor pharmacokinetics associated with peptide reagents, it acts in vivo to protect mice against experimentally induced bone loss, suggesting that development of agents that prevent the interaction of RANK CRD3 with RANKL may prove to be useful for the treatment of diseases where bone resorption is increased, such as osteoporosis, rheumatoid arthritis, and osteolytic bone metastases.

\section{Methods}

Materials. The WP9QY (YCWSQYLCY) and control (YCWSQNLCY) peptides were synthesized, and the activity of WP9QY against the TNF- $\alpha-T N F R$ interaction was assayed as described previously (26). Recombinant human M-CSF was from Calbiochem or R\&D Systems. Recombinant soluble human RANKL was from ProStrakan and Wako Pure Chemical Industries Inc. Recombinant human OPG was from PeproTech. TNFR(I)-deficient mice (C57BL/6), TNFR(II)-deficient mice (C57BL/6), TNFR(I)/TNFR(II)deficient mice (129/B6), and genetically matched wild-type controls were produced by breeding mice obtained from Jackson Laboratory. Antibodies

\section{Table 2}

Histomorphometric analysis of the protective effect of WP9QY on bone loss induced by low dietary calcium (proximal tibia)

$\begin{array}{lccc}\text { Parameter } & \begin{array}{c}\text { Normal Ca/ } \\ \text { vehicle }\end{array} & \begin{array}{c}\text { Low Ca/ } \\ \text { vehicle }\end{array} & \begin{array}{c}\text { Low Ca/WP9aY } \\ \mathbf{( 9 ~} \mathbf{~ m g} / \mathbf{k g})\end{array} \\ \text { BV/TV }(\%) & 9.74 \pm 1.05 & 4.44 \pm 1.55^{\mathrm{A}} & 10.28 \pm 1.28^{\mathrm{B}} \\ \text { TbTh }(\mu \mathrm{m}) & 33.21 \pm 3.34 & 28.19 \pm 3.60^{\mathrm{C}} & 31.57 \pm 2.85 \\ \text { TbN }(\mathrm{no} . / \mathrm{mm}) & 2.95 \pm 0.39 & 1.58 \pm 0.52^{\mathrm{A}} & 3.26 \pm 0.29^{\mathrm{D}} \\ \text { TbSp }(\mu \mathrm{m}) & 310.2 \pm 44.6 & 653.4 \pm 193.1^{\mathrm{A}} & 277.5 \pm 25.7 \mathrm{D} \\ \text { NOC/BS }(\mathrm{no} . / \mathrm{mm}) & 2.52 \pm 0.48 & 4.06 \pm 1.40^{\mathrm{C}} & 1.98 \pm 0.98^{\mathrm{B}} \\ \text { OcS/BS }(\%) & 8.53 \pm 1.42 & 14.07 \pm 4.18^{\mathrm{C}} & 9.07 \pm 5.57^{\mathrm{E}} \\ \text { ObS/BS }(\%) & 22.21 \pm 5.41 & 31.47 \pm 6.15^{\mathrm{C}} & 24.15 \pm 6.58\end{array}$

AP $<0.005$ versus normal-calcium group. ${ }^{B} P<0.005$ versus low-calcium group. ${ }^{C} P<0.05$ versus normal-calcium group. ${ }^{D} P<0.0005$ versus lowcalcium group. ${ }^{\mathrm{E} P}<0.05$ versus low-calcium group. 

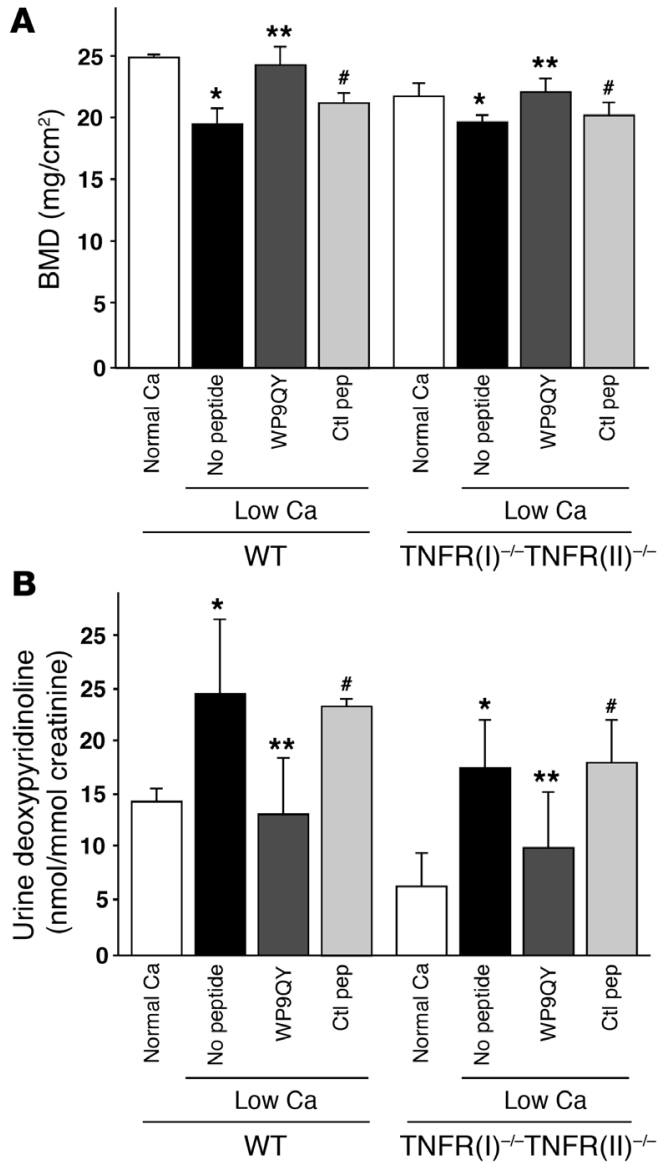

\section{Figure 8}

WP9QY inhibits the bone loss induced by low dietary calcium in mice that lack TNF receptors. After a 3-day acclimation period on normal-calcium diet, mice that lack both TNFR(I)/p55 and TNFR(II)/p75 and genetically matched wild-type mice were maintained on low-calcium diet for 7 days, during which time they were treated with vehicle, WP9QY, or the control peptide (ctl pep) by infusion pump as described in Methods. BMD was measured by DEXA (A), and urine deoxypyridinoline cross-links (B) were determined as described in Methods. ${ }^{\star} P<0.05$ versus genetically matched normal-calcium group; **not significant versus genetically matched normal-calcium group, $P<0.05$ versus genetically matched low-calcium group; ${ }^{P} P<0.05$ versus genetically matched normal-calcium group, not significant versus genetically matched low-calcium group, $P<0.05$ versus genetically matched low-calcium plus WP9QY group.

and fusion proteins were from Cell Signaling Technology, except for the anti-Erk2 antibody, the anti-glycogen synthase kinase 3 antibody and the anti-p65 monoclonal antibody (all from Santa Cruz Biotechnology Inc.).

Osteoclast-like cell generation. Murine bone marrow cells were cultured in 48well plates at a cell density of $1.5 \times 10^{5} \mathrm{cells} / \mathrm{cm}^{2}$ in Minimal Essential Medium Eagle, Alpha Modification (Sigma-Aldrich), containing 10\% FBS, $100 \mathrm{U} /$ $\mathrm{ml}$ penicillin, $100 \mu \mathrm{g} / \mathrm{ml}$ streptomycin, $25 \mathrm{ng} / \mathrm{ml} \mathrm{M}-\mathrm{CSF}$, and the desired concentration of RANKL for 4 days, with a change of culture medium on day 3 . Cells were stained for TRAP and counted as described previously (45).

Modeling the RANKL-WP9QY and RANKL-WP9QY-RANK complexes. The RANKL-RANK complex model was built by homology modeling with Modeler module installed in Insight II (Accelrys Software Inc.), using the crystal structure of the TNFR-TNF- $\beta$ complex (Protein Data Bank code: 1TNR) as a template. The complex structure was energy minimized by use of the molecular mechanics program Discover 3 (Accelrys Software Inc.), until the root mean square deviation became $0.1 \mathrm{kcal} / \mathrm{mol} / \AA^{2}$. The WP9QY peptide structure was generated by separating the peptide fragment that corresponds to the WP9QY peptide from the model structure of RANK. After replacing the residues for the WP9QY peptide and forming the disulfide bond between cysteine residues in positions 2 and 8 of the peptide, the peptide structure in the complex form was energy minimized with Discover 3 . Then the peptide and residues of RANK within $12 \AA$ of the peptide were structure optimized with the molecular dynamics calculation. The optimized complex structure was selected from 100 energy-minimized structures sampled by the molecular dynamics calculations at $298^{\circ} \mathrm{K}$ for $100 \mathrm{ps}$.

The RANKL structure of the RANKL-RANK complex model was superimposed with the RANKL structure of the RANKL-WP9QY complex model. Examination of the pivoting points for the motion of the C-terminal moiety of RANK suggested that the rotation of the backbone at Ala114 best avoids the steric interference between the peptide and the C-terminal domain of RANK, so the C-terminal domain starting from Ala114 was moved outward by rotating the $\phi$ bond of the backbone at Ala114, and the final model of the RANKL-WP9QY-RANK complex was obtained from the initial complex structure by energy minimization with Discover 3.

Analysis of peptide-RANKL and RANKL-RANK binding by surface plasmon resonance. WP9QY binding to SRANKL was analyzed using an IAsys Manual System biosensor (Thermo Electron Corp.). WP9QY or the control peptide was coupled to the cuvette (approximately $0.33 \mathrm{ng} / \mathrm{mm}^{2}$ ), and the binding of sRANKL to the immobilized peptides was performed according to the manufacturer's protocol. The binding of RANKL to immobilized RANK was analyzed using a Biacore 3000.

RANK signaling assays. RAW 264.7 cells were maintained in DMEM (46). After overnight serum starvation, cells were treated with $2.0 \mu \mathrm{g} / \mathrm{ml}$ sRANKL together with various concentrations of WP9QY, the Y6N control peptide (50 $\mu \mathrm{M})$, or OPG $(0.5 \mu \mathrm{g} / \mathrm{ml})$, as indicated, for 20 minutes. Total cell lysates were prepared and analyzed by Western blotting as described previously (47).

To analyze NF- $\mathrm{KB}$ nuclear translocation, RAW 264.7 cells were treated for 20 minutes with $2.0 \mu \mathrm{g} / \mathrm{ml}$ sRANKL, with or without $50 \mu \mathrm{M}$ WP9QY, and were then fixed, permeabilized, and incubated with anti-p65 antibody followed by fluorescein-conjugated secondary antibody and examined using a confocal imaging system (LSM 510; Zeiss) as described previously (47).

To analyze the induction of NFATc1 and c-Fos expression, bone marrow cells from 8-week-old C57BL/6J mice were cultured overnight in minimal essential medium, alpha modification, containing 10\% FBS, 100 $\mathrm{U} / \mathrm{ml}$ penicillin, and $100 \mu \mathrm{g} / \mathrm{ml}$ streptomycin. Nonadherent cells were recovered, replated in 6-well plates at a density of $2.5 \times 10^{5}$ cells/well, and cultured for 2 days in medium containing $10 \mathrm{ng} / \mathrm{ml} \mathrm{M-CSF}$. Cells were washed with medium and cultured for an additional 48 hours with 10 $\mathrm{ng} / \mathrm{ml} \mathrm{M-CSF}, 0.1 \mu \mathrm{g} / \mathrm{ml} \mathrm{RANKL}$, and the indicated concentrations of WP9QY or OPG. Cells were washed once in cold PBS; lysed with modified RIPA buffer (50 mM Tris- $\mathrm{HCl}$ pH 7.5, $150 \mathrm{mM} \mathrm{NaCl}, 0.1 \%$ NP40, 0.25\% sodium deoxycholate, $1 \mathrm{mM}$ EGTA) supplemented with $1 \mathrm{mM} \mathrm{NaF}, 1 \mathrm{mM}$ $\mathrm{Na}_{3} \mathrm{VO}_{4}, 10 \mu \mathrm{g} / \mathrm{ml}$ leupeptin, $10 \mu \mathrm{g} / \mathrm{ml}$ aprotinin, $10 \mu \mathrm{g} / \mathrm{ml}$ pepstatin, and $1 \mathrm{mM}$ phenylmethylsulfonylfluoride; and analyzed for NFATc1 and c-Fos protein by Western blotting.

Erk phosphorylation was assayed by Western blotting total cell lysates with anti-phospho-Erk antibody. JNK kinase activity and Akt kinase activity were assayed using SAPK/JNK Assay Kit and Akt Kinase Assay Kit (Cell Signaling Technology), respectively, according to the manufacturer's instructions, except that the concentration of ATP was $200 \mu \mathrm{M}$.

EMSA was performed using nuclear extracts from treated RAW 264.7 cells and a [ $\left.{ }^{32} \mathrm{P}\right]$-labeled double-stranded oligonucleotide containing an NF- $\kappa \mathrm{B}$ binding site ( $5^{\prime}$-GAGTTGAGGGGACTTTCCCAGGC- $\left.3^{\prime}\right)$ as described previously (48). 
Pit formation assay. Authentic murine osteoclasts were isolated and the in vitro bone resorption assay (pit assay) was performed as described previously $(45,49)$. Briefly, slices of dentine $(350 \mu \mathrm{m})$ were prepared using a low-speed diamond saw (EXACT) under water irrigation. One surface of these slices was lightly polished, washed in 70\% ethanol, and sterilized by ultraviolet irradiation. Isolated osteoclasts from 3-day-old CD-1 mice were seeded on the polished surface of dentine slices placed in 48-well dishes. After 48 hours of culture, the dentine slices were fixed with $0.25 \%$ glutaraldehyde solution and stained for TRAP. The area and volume of resorption pits were measured with a Laser Color 3D profile confocal microscope (VK8510K; Keyence Corp.) using WinRoof image analyzing software (Mitani Corp.). Horizontal and vertical scanning was performed, and the resultant images were combined to reproduce the surface characteristics 3-dimensionally. The images were displayed at a resolution of $1,024 \times 768$ pixels.

Determination of the effect of WP9QY on in vivo bone resorption. The effect of WP9QY on ovariectomy-induced bone resorption was examined as described previously (50), with some modifications. Four groups $(n=5)$ of 12-week-old female C57BL/6J mice were housed singly in metabolic cages (Metabolica; Sugiyamagen Corp.) to allow the collection of urine samples. After weighing, 3 groups underwent bilateral OVX, and the fourth group underwent sham ovariectomy. WP9QY solution or vehicle (10\% DMSO in PBS) was infused continuously via osmotic minipumps (model 2002; ALZA Corp.) as follows: sham/vehicle, OVX/vehicle, OVX/WP9QY at $0.7 \mathrm{mg} / \mathrm{kg} / \mathrm{d}$; and OVX/WP9QY at $2.1 \mathrm{mg} / \mathrm{kg} / \mathrm{d}$. Minipumps were implanted immediately after ovariectomy and replaced after 2 weeks (total 4 weeks) (50). After 4 weeks, lumbar vertebrae and tibiae were dissected free from soft tissue and fixed in cacodylate-buffered glutaraldehyde/formalin $(2.5 \% / 4 \%)$ fixative ( $\mathrm{pH}$ 7.4) for histomorphometric analysis. Uterine wet weight was measured to confirm successful ovariectomy.

The effect of WP9QY on bone loss induced by low dietary calcium was examined in mice of 2 different genetic backgrounds, CD-1 and 129/B6. Initially, twenty 6-week-old male CD-1 mice were housed singly in metabolic cages and fed a semisynthetic diet using the pair feeding technique as described previously (51) with some modifications. All mice were fed a normal diet for 3 days and then divided into a normal-calcium group (diet containing $0.5 \%$ calcium and $0.35 \%$ phosphorus) and 3 low-calcium groups (diet containing $0.05 \%$ calcium and $0.35 \%$ phosphorus) $(n=5)$. The low-calcium groups were injected subcutaneously every 3 hours with $9 \mathrm{mg} / \mathrm{kg}$ or $24 \mathrm{mg} / \mathrm{kg}$ of the WP9QY peptide or with vehicle (PBS). The normal-calcium group was injected with vehicle. The mice were sacrificed 48 hours after the start of the low-calcium diet/treatment regimen (3 hours after the last injection), and lumbar vertebrae and tibiae were dissected free from soft tissue and fixed in cacodylate-buffered glutaraldehyde/formalin (2.5\%/4\%) fixative ( $\mathrm{pH} 7.4)$ for histomorphometric analysis.

To determine whether WP9QY inhibited bone loss independently of TNF/TNFR signaling, 20 mice lacking both the p55 TNFR(I) and the p75
TNFR(II) receptors and genetically matched wild-type mice were housed separately in 8 groups (4 groups per genotype; normal-calcium diet plus vehicle, low-calcium diet plus vehicle, low-calcium diet plus WP9QY, $4 \mathrm{mg} / \mathrm{kg} / \mathrm{d}$, and low-calcium diet plus the $\mathrm{Y} 6 \mathrm{~N}$ peptide) and fed a normal diet for 3 days. Peptides were administered using infusion pumps starting at the day of the change from normal diet to low-calcium diet. All animal experiments were approved by the Yale University School of Medicine Animal Care and Use Committee or the Tokyo Medical and Dental University Animal Care and Use Committee.

The urinary deoxypyridinoline levels were measured by ELISA (52), using the Metra DPD EIA Kit (Quidel Corp.).

Measurement of BMD and histomorphometric analysis. Tibiae and vertebrae were dissected, fixed in cacodylate-buffered glutaraldehyde/formalin (2.5\%/4\%) fixative ( $\mathrm{pH}$ 7.4) for 3 days, and washed with PBS. The BMD of tibiae and vertebrae was measured by dual energy X-ray absorptiometry (DEXA) (DCS600R; Aloca) or pQCT (XCT Research SA+; Stratec Medizintechnik GmbH) as noted. Specimens were embedded using standard procedures in methylmethacrylate resin. Standard histomorphometric measurements (53) were performed on 5 - $\mu \mathrm{m}$ toluidine blue-stained sections using the KS400 Image analyzing system (Zeiss) as described previously (45).

Statistics. Data are presented as mean \pm SD. Multiple intergroup comparisons were performed by 1 -way ANOVA. When a significant $F$ ratio was identified, groups were compared using Fisher's protected least-significant difference post-hoc test. The difference was considered significant when $P<0.05$.

\section{Acknowledgments}

We thank T. Sato, Y. Ito, K. Kayamori, A. Yamamoto, H. Hotokezaka, S. Harumiya, and S. Kim for technical assistance. We also thank H. Ito (Hitachi High-Technologies Corp.) for the IAsys assay. We are grateful to S. Ejiri, H. Takayanagi, E. Jimi, and S. Tanaka for helpful suggestions. This work was supported by grants from the NIH (DE-04724 and AR-42927) and from ProSkelia Pharmaceuticals to R. Baron, a grant from the Center of Excellence Program for Frontier Research on Molecular Destruction and Reconstruction of Tooth and Bone to H. Saito, and by grants from the Ministry of Education, Science and Culture, Japan, to K. Aoki (12671802, 13557151, 14370589, 16390530, and 17659584) and K. Ohya (16209053).

Received for publication June 23, 2004, and accepted in revised form March 7, 2006.

Address correspondence to: Roland Baron, Department of Orthopaedics, Yale University School of Medicine, PO Box 20804, New Haven, Connecticut 06520-8044, USA. Phone: (203) 785-5986; Fax: (203) 785-2744; E-mail: roland.baron@yale.edu.
1. Anderson, D.M., et al. 1997. A homolog of the TNF receptor and its ligand enhance T-cell growth and dendritic-cell function. Nature. 390:175-179.

2. Suda, T., et al. 1999. Modulation of osteoclast differentiation and function by the new members of the tumor necrosis factor receptor and ligand families. Endocr. Rev. 20:345-357.

3. Wong, B.R., et al. 1997. TRANCE is a novel ligand of the tumor necrosis factor receptor family that activates c-Jun $\mathrm{N}$-terminal kinase in T cells. J. Biol. Chem. 272:25190-25194.

4. Lacey, D.L., et al. 1998. Osteoprotegerin ligand is a cytokine that regulates osteoclast differentiation and activation. Cell. 93:165-176.

5. Yasuda, H., et al. 1998. Osteoclast differentiation factor is a ligand for osteoprotegerin/osteoclastogenesis-inhibitory factor and is identical to TRANCE/
RANKL. Proc. Natl. Acad. Sci. U. S. A. 95:3597-3602.

6. Boyle, W.J., Simonet, W.S., and Lacey, D.L. 2003. Osteoclast differentiation and activation. Nature. 423:337-342

7. Teitelbaum, S.L., and Ross, F.P. 2003. Genetic regulation of osteoclast development and function. Nat. Rev. Genet. 4:638-649.

8. Lam, J., et al. 2000. TNF- $\alpha$ induces osteoclastogenesis by direct stimulation of macrophages exposed to permissive levels of RANK ligand. J. Clin. Invest. 106:1481-1488.

9. Roggia, C., et al. 2001. Up-regulation of TNF-producing $\mathrm{T}$ cells in the bone marrow: a key mechanism by which estrogen deficiency induces bone loss in vivo. Proc. Natl. Acad. Sci. U. S. A. 98:13960-13965.

10. Cenci, S., et al. 2000. Estrogen deficiency induces bone loss by enhancing T-cell production of TNF- $\alpha$.
J. Clin. Invest. 106:1229-1237.

11. Feldmann, M., and Maini, R.N. 2001. Anti-TNF alpha therapy of rheumatoid arthritis: what have we learned? Annu. Rev. Immunol. 19:163-196.

12. Redlich, K., et al. 2002. Tumor necrosis factor alpha-mediated joint destruction is inhibited by targeting osteoclasts with osteoprotegerin. Arthritis Rheum. 46:785-792.

13. Zwerina, J., et al. 2004. Single and combined inhibition of tumor necrosis factor, interleukin-1, and RANKL pathways in tumor necrosis factor-induced arthritis: effects on synovial inflammation, bone erosion, and cartilage destruction. Arthritis Rheum. 50:277-290.

14. Burgess, T.L., et al. 1999. The ligand for osteoprotegerin (OPGL) directly activates mature osteoclasts. J. Cell Biol. 145:527-538. 
15. Simonet, W.S., et al. 1997. Osteoprotegerin: a novel secreted protein involved in the regulation of bone density. Cell. 89:309-319.

16. Yasuda, H., et al. 1998. Identity of osteoclastogenesis inhibitory factor (OCIF) and osteoprotegerin (OPG): a mechanism by which OPG/OCIF inhibits osteoclastogenesis in vitro. Endocrinology. 139:1329-1337.

17. Kong, Y.-Y., et al. 1999. OPGL is a key regulator of osteoclastogenesis, lymphocyte development and lymph-node organogenesis. Nature. 397:315-323.

18. Jones, E.Y. 2000. The tumour necrosis factor receptor family: life or death choices. Curr. Opin. Struct. Biol. 10:644-648.

19. Locksley, R.M., Killeen, N., and Lenardo, M.J. 2001. The TNF and TNF receptor superfamilies: integrating mammalian biology. Cell. 104:487-501.

20. Lam, J., Nelson, C.A., Ross, F.P., Teitelbaum, S.L., and Fremont, D.H. 2001. Crystal structure of the TRANCE/RANKL cytokine reveals determinants of receptor-ligand specificity. J. Clin. Invest. 108:971-979. doi:10.1172/JCI200113890.

21. Eck, M.J., and Sprang, S.R. 1989. The structure of tumor necrosis factor- $\alpha$ at 2.6 A resolution. J. Biol. Chem. 264:17595-17605.

22. Banner, D.W., et al. 1993. Crystal structure of the soluble human $55 \mathrm{kd}$ TNF receptor-human TNF $\beta$ complex: implications for TNF receptor activation. Cell. 73:431-445.

23. Hymowitz, S.G., et al. 1999. Triggering cell death: the crystal structure of Apo2L/TRAIL in a complex with death receptor 5. Mol. Cell. 4:563-571.

24. Mongkolsapaya, J., et al. 1999. Structure of the TRAIL-DR5 complex reveals mechanisms conferring specificity in apoptotic initiation. Nat. Struct. Biol. 6:1048-1053.

25. Naismith, J.H., and Sprang, S.R. 1996. Tumor necrosis factor receptor superfamily. J. Inflamm. 47:1-7.

26. Takasaki, W., Kajino, Y., Kajino, K., Murali, R., and Greene, M.I. 1997. Structure-based design and characterization of exocyclic peptidomimetics that inhibit TNF $\alpha$ binding to its receptor. Nat. Biotechnol. 15:1266-1270.

27. Idriss, H.T., and Naismith, J.H. 2000. TNF $\alpha$ and the TNF receptor superfamily: structure-function relationship(s). Microsc. Res. Tech. 50:184-195.

28. Bajorath, J. 1998. From tumor necrosis factor receptor to RANK, from the selectins and link proteins to CD44: new molecular models of cell surface receptors and analysis of specificity determinants.
J. Mol. Model. 4:239-249.

29. Singh, J., et al. 1998. The role of polar interactions in the molecular recognition of CD40L with its receptor CD40. Protein Sci. 7:1124-1135.

30. Abu-Amer, Y., et al. 2000. Tumor necrosis factor receptors types 1 and 2 differentially regulate osteoclastogenesis. J. Biol. Chem. 275:27307-27310.

31. Azuma, Y., Kaji, K., Katogi, R., Takeshita, S., and Kudo, A. 2000. Tumor necrosis factor- $\alpha$ induces differentiation of and bone resorption by osteoclasts. J. Biol. Chem. 275:4858-4864.

32. Kobayashi, K., et al. 2000. Tumor necrosis factor alpha stimulates osteoclast differentiation by a mechanism independent of the ODF/RANKLRANK interaction. J. Exp. Med. 191:275-286.

33. Seto, H., Aoki, K., Kasugai, S., and Ohya, K. 1999. Trabecular bone turnover, bone marrow cell development, and gene expression of bone matrix proteins after low calcium feeding in rats. Bone. 25:687-695.

34. Dougall, W.C., et al. 1999. RANK is essential for osteoclast and lymph node development. Genes Dev 13:2412-2424.

35. Li, J., et al. 2000. RANK is the intrinsic hematopoietic cell surface receptor that controls osteoclastogenesis and regulation of bone mass and calcium metabolism. Proc. Natl. Acad. Sci. U. S. A. 97:1566-1571.

36. Hsu, H., et al. 1999. Tumor necrosis factor receptor family member RANK mediates osteoclast differentiation and activation induced by osteoprotegerin ligand. Proc. Natl. Acad. Sci. U. S. A. 96:3540-3545.

37. McClung, M.R., et al. 2004. AMG 162 increases bone mineral density (BMD) within 1 month in postmenopausal women with low BMD. J. Bone Miner. Res. 19(Suppl. 1):S20.

38. Cheng, X., et al. 2004. Disabling of receptor activator of nuclear factor-kappaB (RANK) receptor complex by novel osteoprotegerin-like peptidomimetics restores bone loss in vivo. J. Biol. Chem. 279:8269-8277.

39. Ito, S., et al. 2002. Crystal structure of the extracellular domain of mouse RANK ligand at 2.2-A resolution. J. Biol. Chem. 277:6631-6636.

40. Yamagishi, J., et al. 1990. Mutational analysis of structure - activity relationships in human tumor necrosis factor-alpha. Protein Eng. 3:713-719.

41. Goh, C.R., Loh, C.S., and Porter, A.G. 1991. Aspartic acid 50 and tyrosine 108 are essential for receptor binding and cytotoxic activity of tumour necrosis factor beta (lymphotoxin). Protein Eng. 4:785-791.

42. Van Ostade, X., Tavernier, J., Prange, T., and Fiers, W. 1991. Localization of the active site of human tumour necrosis factor (hTNF) by mutational analysis. EMBO J. 10:827-836

43. Boldin, M.P., et al. 1995. Self-association of the "death domains" of the p55 tumor necrosis factor (TNF) receptor and Fas/APO1 prompts signaling for TNF and Fas/APO1 effects. J. Biol. Chem. 270:387-391.

44. Naismith, J.H., Devine, T.Q., Kohno, T., and Sprang, S.R. 1996. Structures of the extracellular domain of the type I tumor necrosis factor receptor. Structure. 4:1251-1262.

45. Aoki, K., et al. 1999. The tyrosine phosphatase SHP-1 is a negative regulator of osteoclastogenesis and osteoclast resorbing activity: increased resorption and osteopenia in $m e^{v} / m e^{v}$ mutant mice. Bone. 25:261-267.

46. Yamamoto, A., et al. 2002. Possible involvement of IкB kinase 2 and MKK7 in osteoclastogenesis induced by receptor activator of nuclear factor $\kappa \mathrm{B}$ ligand. J. Bone Miner. Res. 17:612-621.

47. Sanjay, A., et al. 2001. Cbl associates with Pyk2 and Src to regulate Src kinase activity, $\alpha_{v} \beta_{3}$ integrinmediated signaling, cell adhesion, and osteoclast motility. J. Cell Biol. 152:181-195.

48. Sabatakos, G., et al. 2000. Overexpression of $\Delta$ FosB transcription factor(s) increases bone formation and inhibits adipogenesis. Nat. Med. 6:985-990.

49. Varghese, B.J., Aoki, K., Shimokawa, H., Ohya, K., and Takagi, K. 2006. Bovine deciduous dentine is more susceptible to osteoclastic bone resorption than permanent dentine: results of quantitative analyses. J. Bone Miner. Metab. In press.

50. Yamamoto, M., et al. 1998. The integrin ligand echistatin prevents bone loss in ovariectomized mice and rats. Endocrinology. 139:1411-1419.

51. Amano, H. 1989. A histomorphometric analysis of the alveolar bone resorption process in calciumdeficient rats. Shika Kiso Igakkai Zasshi. 31:404-416.

52. Nagahama, K., et al. 2004. The deficiency of immunoregulatory receptor PD-1 causes mild osteopetrosis. Bone. 35:1059-1068.

53. Parfitt, A.M., et al. 1987. Bone histomorphometry: standardization of nomenclature, symbols, and units. Report of the ASBMR Histomorphometry Nomenclature Committee. J. Bone Miner. Res. 2:595-610. 